\title{
К ВОПРОСУ О ГОСУДАРСТВЕННОМ СТРАТЕГИЧЕСКОМ ПЛАНИРОВАНИИ В ОБЕСПЕЧЕНИИ ЭКОНОМИЧЕСКОЙ БЕЗОПАСНОСТИ
}

\begin{abstract}
Аннотация: Формирование системы управления национальной безопасностью с учетом как тактических, так и стратегических задач должно обеспечивать не просто «защиту» от возникиих (существуюших) угроз, но и прогнозирование, предупреждение и профилактику внутренних и внешних угроз с целью обеспечения стабильного развития общества. Следовательно, одним из основных принципов стратегического планирования должна стать взаимозависимость мер социально-экономического развития Российской Федерации и обеспечения экономической безопасности.В данной связи представляется необоснованным отход от последовательного развития и закрепления в законодательных актах вопросов применения стратегического планирования для обеспечения национальной безопасности. Взаимозависимость устойчивого развития и обеспечения экономической безопасности определяет необходимость научной обоснованности стратегических решений и требует исследования вопросов стратегического планирования В статье определена необходимость создания системы государственного стратегического планирования, определяющей взаимозависимость мер социально-экономического развития Российской Федерации и обеспечения экономической безопасности, что позволит устранить недостатки, которые приводят к разрозненности сил и средств обеспечения национальной безопасности и позволит сконщентрировать усилия на тех направлениях безопасности, которые достигли и превысили кризисные значения.
\end{abstract}

Ключевые слова: угрозы, доктрина, экономическая безопасность, обеспечение, стратегическое планирование, стратегия, государство, система, защита, критерии.

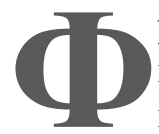

ундаментальное положение о взаимосвязи и взаимозависимости устойчивого развития и обеспечения экономической безопасности делает крайне важной проблему научной обоснованности стратегических решений и требует высокой ответственности государственных структур при их принятии. В соответствии с этим одним из наиболее востребованных методов государственного управления экономикой становится система стратегического планирования, которая в различных формах практически используется большинством экономически развитых стран.

В последнее время одним из направлений научных исследований в области обеспечения экономической безопасности являются вопросы стратегического планирования. Академические институты образуют научные подразделения по актуализации данной проблемы, проводят научные конференции. Так в 2010 году в Финансовом университете был создан
«Институт проблем экономической безопасности и стратегического планирования» ${ }^{1}$, факультет национальной безопасности РАНХИГС в 2012 году провел научно-практическую конференцию «Стратегическое управление в сфере национальной безопасности России: субъекты, ресурсы, технологии» ${ }^{2}$.

В 2012 году в Госдуму внесен правительственный проект закона «О государственном стратегическом планировании», разработанный в соответствии с Указом Президента РФ от 7 мая 2012 года №596 «О долгосрочной государственной экономической политике». Законопроект определяет основы го-

\footnotetext{
http://www.fa.ru/Pages/home.aspx [Электронный pecypc] Режим доступа: свободный

2 http://www.rane.ru/novosti-media/konferencii-seminary [Электронный ресурс] - Режим доступа: свободный

3 Указ Президента РФ от 7 мая 2012 года №596 «О долгосрочной государственной экономической политике».
} 
сударственного стратегического планирования в Российской Федерации, координации государственного стратегического управления и бюджетной политики, полномочия и функции органов государственной власти, субъектов РФ и порядок их взаимодействия с общественными, научными организациями в области стратегического планирования. Ключевая идея законопроекта - создать правовую основу для разработки, построения и функционирования комплексной системы государственного стратегического планирования в области социально-экономического развития и национальной безопасности России.

Такая система будет способна повысить качество жизни населения и обеспечить безопасность страны. В последнее время решения в оборонной, социальной, технологической и экономической сферах приобретают долгосрочный стратегический характер. Поэтому возникла необходимость в наборе ряда управленческих инструментов. Согласно законопроекту последними могут стать государственное прогнозирование, программно-целевое и территориальное планирование, мониторинг их реализации. Все это и образует рассматриваемую целостную систему.

Однако представленный на утверждение законопроект практически не прописывает сущность инструментов обеспечения национальной безопасности. В данной связи необходимо отметить утрату некоторых утвержденных ранее официальных документов в области обеспечения национальной безопасности. Так, с принятием Закона «О государственном стратегическом планировании» утратит силу Указ Президента Российской Федерации от 12 мая 2009 г. № 536 «Об Основах стратегического планирования в Российской Федерации» ${ }^{4}$, который стал первой попыткой законодательного регулирования и объединения двух важнейших категорий «экономическая безопасность» и «стратегическое планирование» на современном этапе.

В данном указе было дано само определение стратегического анализа уровня устойчивого развития Российской Федерации и состояния национальной безопасности в форме научно обоснованной системы оценок условий и факторов, формирующих внутренние и внешние угрозы национальной безопасности, включая стратегические риски для устойчивого развития государства на долгосрочную

4 Указ Президента Российской Федерации от 12 мая 2009 г. № 536 «Об Основах стратегического планирования в Российской Федерации» перспективу. Следовательно, обоснована необходимость взаимосвязи и взаимозависимости данных категорий для обеспечения поступательного развития экономики.

Одним из основных принципов стратегического планирования, сказано в Указе, является взаимозависимость мер социально-экономического развития Российской Федерации и обеспечения экономической безопасности.

Таким образом, обеспечение безопасности - это не просто «защита» от возникших (существующих) угроз, но и прогнозирование, предупреждение и профилактика внутренних и внешних угроз с целью обеспечения стабильного развития общества. Необходимо сформировать систему управления национальной безопасностью таким образом, чтобы в ней были учтены как тактические, так и стратегические аспекты, что позволит заранее очерчивать круг угроз и использовать уже имеющиеся инструменты.

Дальнейшее развитие законодательства о применении инструментов стратегического планирования для обеспечения национальной безопасности нашло отражение в Указе Президента Российской Федерации от 12 мая 2009 г. № 537, утверждающем Стратегию национальной безопасности Российской Федерации до 2020 года ${ }^{5}$, которая на сегодняшний день является базовым документом по планированию развития системы обеспечения национальной безопасности Российской Федерации и представляет собой официально признанную систему стратегических приоритетов, целей и мер в области внутренней и внешней политики, определяющих состояние национальной безопасности и уровень устойчивого развития государства в краткосрочной, среднесрочной и долгосрочной перспективе.

Важным стратегическим документом в области обеспечения экономической безопасности, и в продолжении проводимой работы, стала Доктрина продовольственной безопасности Российской Федерации ${ }^{6}$, определяющая официальные взгляды на цели, задачи и основные направления государственной экономической политики в области обеспечения продовольственной безопасности Российской

\footnotetext{
5 Стратегия национальной безопасности Российской Федерации до 2020 года. Утверждена Указом Президента Российской Федерации от 12 мая 2009 г. № 537.

6 Доктрина продовольственной безопасности Российской Федерации. Утверждена Указом Президента Российской Федерации от 30 января 2010 года № 120.
} 


\section{Национальная безопасность - № 3(32) • 2014}

Федерации. В Доктрине продовольственной безопасности Российской Федерации развиваются положения Стратегии национальной безопасности Российской Федерации до 2020 года, касающиеся продовольственной безопасности Российской Федерации, учтены нормы Морской доктрины Российской Федерации на период до 2020 года. Важным представляется тот факт, что в основу разработки Доктрины продовольственной безопасности Российской Федерации положены требования двух указанных документов и она целиком направлена на обеспечение продовольственной безопасности ${ }^{7}$ Следовательно, подход, определенный до этого уже положен в основу принимаемых документов.

В Доктрине продовольственной безопасности Российской Федерации также определены показатели продовольственной безопасности Российской Федерации и критерии их оценки, к которым относят систему показателей:

- в сфере потребления;

- в сфере производства и национальной конкурентоспособности;

- в сфере организации управления.

Следующим важным примером использования инструментов стратегического планирования для обеспечения национальной безопасности является Энергетическая стратегия России на период до 2030 года $^{8}$, где также определены индикаторы энергетической безопасности, к которым отнесены (Приложение 2):

- рост душевого энергопотребления;

- $\quad$ рост душевого электропотребления;

- $\quad$ рост душевого потребления моторного топлива;

- снижение среднего износа основных производственных фондов;

- ликвидация дефицита и поддержание устойчивого резерва электро- и теплогенерирующих мощностей.

В данной связи представляется необоснованным отход от последовательного развития и закрепления в законодательных актах вопросов применения стратегического планирования для обеспечения национальной безопасности.

\footnotetext{
7 Указ Президента Российской Федерации от 12 мая 2009 г. № 536 «Об Основах стратегического планирования в Российской Федерации».

8 Энергетическая стратегия России на период до 2030 года. Утверждена распоряжением Правительства Российской Федерации от 13 ноября 2009 г. № 1715-р.
}

Предложенный правительством законопроект «О государственном стратегическом планировании» не рассматривает затронутые и уже положенные в основу стратегического планирования категории национальной и экономической безопасности. Остановимся на этом подробнее.

В ст. 1 законопроекта определено, что «государственное стратегическое планирование включает государственное стратегическое планирование социально-экономического развития и государственное стратегическое планирование обеспечения национальной безопасности». То есть данные категории используются «раздельно», не учитывается их существенная взаимосвязь и взаимозависимость.

П.3. ст.1 определил, что данный закон в части государственного стратегического планирования обеспечения национальной безопасности в области обороны, военного строительства и оборонного заказа, правопорядка и гражданской обороны применяется с учетом законодательства Российской Федерации, регулирующего правоотношения в сфере национальной безопасности. Значит, определена национальная безопасность в области обороны, военного строительства и оборонного заказа, правопорядка и гражданской обороны, и не учтена экономическая безопасность. Возникает вопрос: «А на какие цели тогда направлено государственное стратегическое планирование социально-экономического развития?».

Далее, при раскрытии сущности государственного стратегического планирования, отмечено, что это «регламентируемая законодательством Российской Федерации деятельность органов государственной власти Российской Федерации, органов государственной власти субъектов Российской Федерации и иных участников процесса государственного стратегического планирования по прогнозированию социально-экономического развития, программноцелевому планированию и стратегическому контролю, направленная на повышение уровня социальноэкономического развития Российской Федерации, рост благосостояния граждан и обеспечение национальной безопасности».

Ни одна статья законопроекта не затрагивает вопросы обеспечения национальной безопасности с использованием инструментов стратегического планирования, что нарушает целостность единого подхода к вопросам ее обеспечения.

После принятия Федерального закона от 28 декабря 2010г. № 390-Ф3 «О безопасности» основ- 
ными объектами безопасности стало государство, общественная безопасность, экологическая безопасность, безопасность личности, иные виды безопасности. Таким образом, Правительство Российской Федерации, разрабатывая законопроект, отошло от выполнения своих полномочий в области обеспечения национальной безопасности'.

Анализ разработанных Стратегий социальноэкономического развития федеральных округов позволил определить, что большинство стратегий также уже разработаны с учетом обеспечения развития и сохранения национальной безопасности.

Так, к Стратегиям социально-экономического развития федеральных округов, разработанных с учетом Стратегии национальной безопасности Российской Федерации до 2020 года ${ }^{10}$, Концепции долгосрочного социально-экономического развития Российской Федерации на период до 2020 года ${ }^{11}$, утвержденной распоряжением Правительства Российской Федерации от 17 ноября 2008 г. № 1662-р, отраслевых и территориальных стратегий и концепций развития относятся:

- Стратегия социально-экономического развития Сибири до 2020 года (Утв. распоряжением Правительства Российской Федерации от 5 июля 2010 г. № 1120-p);

- Стратегия социально-экономического развития Северо-Западного федерального округа на период до 2020 года (Утв. распоряжением Правительства Российской Федерации от 18 ноября 2011 г. № 2074-р);

- Стратегия социально-экономического развития Северо-Кавказского федерального округа до 2025 года (Утв. распоряжением Правительства Российской Федерации от 6 сентября 2010 г. №1485-p);

- Стратегия социально-экономического развития Уральского Федерального округа (Утв. распоряжением Правительства Российской Федерации от 6 октября 2011 г. № 1757-p);

\footnotetext{
9 Федеральный закон от 28 декабря 2010 г. № 390-Ф3 «О безопасности».

10 Стратегия национальной безопасности Российской Федерации до 2020 года. Утверждена Указом Президента Российской Федерации от 12 мая 2009 г. № 537.

11 Концепция долгосрочного социально-экономического развития Российской Федерации на период до 2020 года. Утверждена распоряжением Правительства Российской Федерации от 17 ноября 2008 г. № 1662-р.
}

- Стратегия социально-экономического развития Приволжского федерального округа на период до 2020 года (Утв. распоряжением Правительства РФ от 7 февраля 2011 г. № 165-p);

- Стратегия социально-экономического развития Южного федерального округа на период до 2020 года (Утв. распоряжением Правительства РФ от 5 сентября 2011 г. № 1538-p);

Две стратегии не содержат ссылок на указанные документы, но внутри них обозначены вызовы и угрозы национальной безопасности, к ним относятся:

- Стратегия социально-экономического развития Дальнего Востока и Байкальского региона на период до 2025 года (Утв. распоряжением Правительства РФ от 28 декабря 2009 г. № 094-p);

- Стратегия социально-экономического развития Центрального федерального округа на период до 2020 года (Утв. распоряжением Правительства Российской Федерации от 6 сентября 2011 г. № 1540-p).

К документам государственного стратегического планирования, разрабатываемым на федеральном уровне, в законопроекте не отнесены стратегии, доктрины, которые уже разработаны и могли быть разработаны с учетом требований обеспечения национальной безопасности.

Вместе с тем, целесообразно отметить, что в состав стратегических документов разумно было бы включить экономические показатели, которые определены в Стратегии национальной безопасности Российской Федерации до 2020 года, являются характеристиками состояния национальной безопасности и предназначаются для оценки состояния национальной безопасности:

- уровень безработицы (доля от экономически активного населения);

- децильный коэффициент (соотношение доходов $10 \%$ наиболее и $10 \%$ наименее обеспеченного населения);

- уровень роста потребительских цен;

- уровень государственного внешнего и внутреннего долга в процентном отношении от валового внутреннего продукта;

- уровень обеспеченности ресурсами здравоохранения, культуры, образования и науки в процентном отношении от валового внутреннего продукта;

- уровень ежегодного обновления вооружения, военной и специальной техники; 


\section{Национальная безопасность - № 3(32) • 2014}

- у уровень обеспеченности военными и инженернотехническими кадрами.

Перечень основных характеристик состояния национальной безопасности может уточняться по результатам ее мониторинга ${ }^{12}$.

В этой связи необходимо создать иерархически увязанную систему государственного стратегического планирования, определяющую взаимозависимость мер социально-экономического развития Российской Федерации и обеспечения экономической безопасности, что позволит устранить указанные недостатки, которые приводят к разрозненности сил и средств обеспечения национальной безопасности и позволит сконцентрировать усилия на тех направлениях безопасности, которые достигли и превысили кризисные значения.

\section{Библиография:}

1. Федеральный закон от 28 декабря 2010г. № 390-Ф3 «О безопасности».

2. Указ Президента РФ от 7 мая 2012 года №596 «О долгосрочной государственной экономической политике».

3. Указ Президента Российской Федерации от 12 мая 2009 г. № 536 «Об Основах стратегического планирования в Российской Федерации».

4. Указ Президента Российской Федерации от 12 мая 2009 г. № 536 «Об Основах стратегического планирования в Российской Федерации

5. Стратегия национальной безопасности Российской Федерации до 2020 года. Утверждена Указом Президента Российской Федерации от 12 мая 2009 г. № 537.

6. Концепция долгосрочного социально-экономического развития Российской Федерации на период до 2020 года . Утверждена распоряжением Правительства Российской Федерации от 17 ноября 2008 г. № 1662-р.

7. Доктрина продовольственной безопасности Российской Федерации. Утверждена Указом Президента Российской Федерации от 30 января 2010 года № 120.

8. Морская доктрина Российской Федерации на период до 2020 года. Утверждена Президентом Российской Федерации 27 июля 2001 г.

9. Энергетическая стратегия России на период до 2030 года. Утверждена распоряжением Правительства Российской Федерации от 13 ноября 2009 г. № 1715-р.

10. http://www.fa.ru/Pages/home.aspx [Электронный pecypc] — Режим доступа: свободный

11. http://www.rane.ru/novosti-media/konferencii-seminary [Электронный ресурс] - Режим доступа: свободный

12. Васильев А.В. Экономическая политика современных государств и России // NB: Экономика, тренды и управление. — 2013. — № 4. — C. 60-87. DOI: 10.7256/2306-4595.2013.4.7056. URL: http://e-notabene.ru/etc/ article_7056.html

13. Моргун О.В.. Понятие и основные особенности мер финансовой безопасности. // Национальная безопасность / nota bene. - 2014. — № 2. - C. 235-243. DOI: 10.7256/2073-8560.2014.2.10792

14. Шульц В.Л., Кульба В.В., Шелков А.Б., Чернов И.В.. Сценарный анализ эффективности управления региональной безопасностью. // Национальная безопасность / nota bene. — 2014. — № 2. - С. 188-206. DOI: $10.7256 / 2073-8560.2014 .2 .1131$

\section{References:}

1. Federal'nyi zakon ot 28 dekabrya 2010 g. № 390-FZ «O bezopasnosti».

2. Ukaz Prezidenta RF ot 7 maya 2012 goda №596 «O dolgosrochnoi gosudarstvennoi ekonomicheskoi politike».

3. Ukaz Prezidenta Rossiiskoi Federatsii of 12 maya 2009 g. № 536 «Ob Osnovakh strategicheskogo planirovaniya v Rossiiskoi Federatsii».

4. Ukaz Prezidenta Rossiiskoi Federatsii ot 12 maya 2009 g. № 536 «Ob Osnovakh strategicheskogo planirovaniya v Rossiiskoi Federatsii

12 Стратегия национальной безопасности Российской Федерации до 2020 года. Утверждена Указом Президента Российской Федерации от 12 мая 2009 г. № 537. 
5. Strategiya natsional'noi bezopasnosti Rossiiskoi Federatsii do 2020 goda. Utverzhdena Ukazom Prezidenta Rossiiskoi Federatsii ot 12 maya 2009 g. № 537.

6. Kontseptsiya dolgosrochnogo sotsial'no-ekonomicheskogo razvitiya Rossiiskoi Federatsii na period do 2020 goda . Utverzhdena rasporyazheniem Pravitel'stva Rossiiskoi Federatsii ot 17 noyabrya 2008 g. № 1662-r.

7. Doktrina prodovol'stvennoi bezopasnosti Rossiiskoi Federatsii. Utverzhdena Ukazom Prezidenta Rossiiskoi Federatsii ot 30 yanvarya 2010 goda № 120 .

8. Morskaya doktrina Rossiiskoi Federatsii na period do 2020 goda. Utverzhdena Prezidentom Rossiiskoi Federatsii 27 iyulya $2001 \mathrm{~g}$.

9. Energeticheskaya strategiya Rossii na period do 2030 goda. Utverzhdena rasporyazheniem Pravitel'stva Rossiiskoi Federatsii ot 13 noyabrya 2009 g. № 1715-r.

10. http://www.fa.ru/Pages/home.aspx [Elektronnyi resurs] — Rezhim dostupa: svobodnyi

11. http://www.rane.ru/novosti-media/konferencii-seminary [Elektronnyi resurs] - Rezhim dostupa: svobodnyi

12. Vasil'ev A.V. Ekonomicheskaya politika sovremennykh gosudarstv i Rossii // NB: Ekonomika, trendy i upravlenie._-2013.—№4.—S.60-87.DOI: 10.7256/2306-4595.2013.4.7056. URL: http://e-notabene.ru/etc/article_7056.html

13. Morgun O.V.. Ponyatie i osnovnye osobennosti mer finansovoi bezopasnosti. // Natsional'naya bezopasnost' / nota bene. — 2014. — № 2. - C. 235-243. DOI: 10.7256/2073-8560.2014.2.10792

14. Shul'ts V.L., Kul'ba V.V., Shelkov A.B., Chernov I.V.. Stsenarnyi analiz effektivnosti upravleniya regional'noi bezopasnost'yu. // Natsional'naya bezopasnost' / nota bene. — 2014. — № 2. — C. 188-206. DOI: 10.7256/20738560.2014 .2 .1131 